\title{
FONTES DE CÁLCIO APLICADAS NO SOLO E SUA RELAÇÃO COM A QUALIDADE DA UVA 'VÊNUS'
}

\author{
MOESES ANDRIGO DANNER ${ }^{2}$, IDEMIR CITADIN³, SIMONE APARECIDA ZOLET SASSO ${ }^{4}$, \\ NELSON ALEXANDRE ZARTH ${ }^{5}$, SÉRGIO MIGUEL MAZARO ${ }^{6}$
}

RESUMO - O objetivo deste trabalho foi avaliar o efeito da aplicação de diferentes fontes de $\mathrm{Ca}^{2+}$ no solo sobre o teor deste nutriente no solo, nas folhas e nos frutos, e sobre atributos físico-químicos e conservação pós-colheita da uva 'Vênus' (Vitis labrusca x V. vinifera). O delineamento foi em blocos ao acaso, com quatro repetições. Utilizaram-se os seguintes tratamentos: T1 - testemunha (sem aplicação de $\mathrm{Ca}^{2+}$ no solo); T2 - cloreto de cálcio; T3 - gesso agrícola; T4 - Nitrabor ${ }^{\mathbb{B}}$; T5 - cal hidratada, e T6 - borra de celulose.

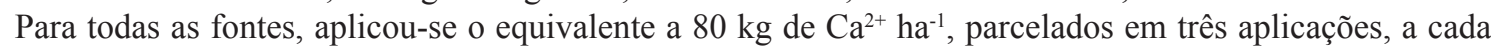
21 dias, a partir do início da brotação da videira. Avaliou-se o teor de macronutrientes no solo, nas folhas e frutos. Na maturação, foram coletados quatro cachos por parcela, sendo dois cachos avaliados por ocasião da colheita e dois cachos mantidos sob temperatura ambiente e atmosfera modificada, sendo avaliados após cinco dias. Em geral, as fontes de $\mathrm{Ca}^{2+}$ proporcionaram maior teor de $\mathrm{Ca}^{2+}$ no solo, nas folhas e nos frutos. $\mathrm{O}$ Nitrabor ${ }^{\circledR}$ e o gesso agrícola aumentaram o peso médio de bagas. As fontes de $\mathrm{Ca}^{2+}$ reduziram a perda de peso, o degrane e a incidência de podridões dos frutos em pós-colheita.

Termos para indexação: Vitis labrusca x V. vinifera, translocação de $\mathrm{Ca}^{2+}$, qualidade de fruto, conservação pós-colheita.

\section{SOURCES OF CALCIUM APPLIED IN THE SOIL AND ITS RELATIONSHIP TO THE QUALITY OF 'VÊNUS' GRAPE}

\begin{abstract}
This work was conducted to evaluate the effects of different sources of $\mathrm{Ca}^{2+}$, applied in the soil, on the content of this nutrient in the soil, in the leaves, and in the fruits; the physico-chemical attributes and the post-harvest conservation of grapes 'Vênus' (Vitis labrusca x V. vinifera). The experiment was carried out in a random block design, with four replications. It was used the following treatments: T1 - control (without application of $\mathrm{Ca}^{2+}$ in the soil); T2 - calcium chloride; T3 - gypsum; T4 - Nitrabor ${ }^{\circledR}$; T5 - hydrated lime; and, T6 - cellulose paste. For all sources was applied the equivalent of $80 \mathrm{~kg}$ of Ca $\mathrm{Ca}^{2+} \mathrm{ha}^{-1}$, in three applications, every 21 days, starting on the leafing time. It was evaluated the content of nutrients in the soil, leaves and fruits. At maturity, four grape clusters were collected in each parcel, two of them were evaluated in the harvest and the other two ones were kept under ambient temperature and modified atmosphere, being evaluated after five days. In general, the sources of $\mathrm{Ca}^{2+}$ promoted higher content of $\mathrm{Ca}^{2+}$ in the soil, leaves and fruits. Nitrabor ${ }^{\circledR}$ and gypsum increased the average weight of berries. The sources of $\mathrm{Ca}^{2+}$ reduced the loss of weight, the abscission and the incidence of fruits rot in post-harvest.
\end{abstract}

Index terms: Vitis labrusca $\mathrm{x}$ V. vinifera, translocation of $\mathrm{Ca}^{2+}$, fruit quality, post-harvest conservation.

\section{INTRODUÇÃO}

A viticultura é uma atividade economicamente importante para o Brasil. A produção nacional em 2007 foi de 1,35 milhão de toneladas, numa área cultivada de 89,9 mil hectares. A exportação de uva de mesa proporcionou receita de US\$ 169,7 milhões, correspondendo a $26,4 \%$ do total de divisas com exportações de frutas. Destaca-se a crescente produção e exportação de variedades sem sementes, preferidas dos consumidores no exterior (Anuário..., 2008).

Um dos fatores que interferem nos aspectos quantitativos e qualitativos em vinhedos é a nutrição mineral, sendo que o $\mathrm{Ca}^{2+}$ é um nutriente requerido em quantidade relativamente grande pela videira. Dechen (1979) observou que a extração de $\mathrm{Ca}^{2+}$ total em um ciclo vegetativo da videira 'Niagara Rosada' foi de $41 \mathrm{~kg} \mathrm{ha}^{-1}$. Por outro lado, Hiroce et al. (1979)

\footnotetext{
'(Trabalho 105-08) Recebido em: 30-04-2008. Aceito para publicação em: 04-05-2009.

${ }^{2}$ Eng. Agr., MSc., Doutorando UFPR, Bolsista CAPES. Prof. Substituto, UTFPR, Campus Pato Branco. moesesandrigo@yahoo.com.br ${ }^{3}$ Eng. Agr., Dr., Prof. Titular, UTFPR, Campus Pato Branco. Via do conhecimento, km 01, Pato Branco-PR. 85503-390 idemir@utfpr.edu.br - autor para correspondência

${ }^{4}$ Eng. Agr., MSc. UTFPR, Campus Pato Branco. iosasso@ibest.com.br

${ }^{5}$ Tecnólogo em Administração Rural, Mestrando UTFPR - Campus Pato branco, nazarth@wln.com.br

${ }^{5}$ Eng. Agr., Dr., Professor Adjunto, UTFPR, Campus Dois Vizinhos. sergio@utfpr.edu.br
} 
observaram diferença entre cultivares quanto ao teor de $\mathrm{Ca}^{2+}$ nos frutos, sendo que a 'Itália' continha 175 $\mathrm{g}$ de $\mathrm{Ca}^{2+}$ em uma tonelada de frutos, enquanto a 'Niagara Rosada' continha 95 g deste nutriente.

A aplicação de $\mathrm{Ca}^{2+}$ em pré-colheita de maçãs aumentou o teor de hemicelulose, pectinas totais e $\mathrm{Ca}^{2+}$ na polpa, diminuindo a velocidade da hidrólise da parede celular, causada pelas enzimas $\beta$-D-galactosidase, poligalacturonases e pectilmetilesterases (Siddiqui \& Bangerth, 1995). Desse modo, por preservar a integridade da parede celular, vários trabalhos demonstram que o $\mathrm{Ca}^{2+}$ auxilia na redução da perda de qualidade pós-colheita de frutos (Lara et al., 2004; Natale et al., 2005; Hernández-Muñoz et al., 2006).

$\mathrm{O}$ padrão de distribuição do $\mathrm{Ca}^{2+}$ na planta dá-se em favor da parte vegetativa, pois o mesmo é transportado quase que exclusivamente pelo xilema, sendo conduzido principalmente pelo fluxo da transpiração. De acordo Ho et al. (1987), menos de 15\% da água para enchimento do fruto é proveniente do xilema e, desta forma, o aporte de $\mathrm{Ca}^{2+}$ para o fruto é muito pequeno.

Diferentes fontes de um mesmo nutriente podem apresentar distintas respostas numa mesma espécie de planta, devido principalmente à formulação química do adubo, que influencia em sua absorção e translocação na planta. Em citros, Natale \& Marchal (2002) observaram que a eficiência de absorção de nitrogênio variou com o tipo de fertilizante nitrogenado utilizado no solo, sendo que sua redistribuição na planta não foi afetada. Fontes de $\mathrm{Ca}^{2+}$ são amplamente testadas em pulverizações de pré e pós-colheita sobre folhas e frutos, principalmente em macieira (Siddiqui \& Bangerth, 1995), videira (Lima et al., 2000) e pessegueiro (Manganaris et al., 2007), visando principalmente a aumentar a conservação pós-colheita dos frutos. Entretanto, ainda há carência de informações sobre a eficiência de diferentes fontes de $\mathrm{Ca}^{2+}$ aplicadas no solo e sua relação com a qualidade de frutos em videira.

Assim, este trabalho teve por objetivo comparar os efeitos de diferentes fontes de $\mathrm{Ca}^{2+}$ aplicadas no solo sobre o teor de $\mathrm{Ca}^{2+}$ no solo, folhas e frutos e sobre atributos físico-químicos e conservação póscolheita da uva 'Vênus'.

\section{MATERIAL E MÉTODOS}

Este trabalho foi realizado em um vinhedo comercial de videira 'Vênus', enxertada sobre 'Paulsen 1103', localizado em Dois Vizinhos-PR (25 50' $56^{\prime \prime} \mathrm{S} ; 53^{\circ} 06^{\prime} 14^{\prime \prime} \mathrm{W} ; 568 \mathrm{~m}$ de altitude). O solo é classificado como Latossolo Vermelho distrófico. $\mathrm{O}$ vinhedo possuía cobertura com plástico "tipo ráfia" e sistema de irrigação por microaspersão. As plantas eram conduzidas no sistema latada, no espaçamento $1,5 \times 2,5 \mathrm{~m}$. Práticas culturais de rotina foram empregadas durante o ciclo de crescimento das plantas, incluindo duas pulverizações foliares com o produto $\operatorname{Sett}^{\circledR}\left(10 \%\right.$ de $\mathrm{Ca}^{2+}$ e $10 \%$ de boro), na concentração de $300 \mathrm{~mL} 100 \mathrm{~L}^{-1}$ de água, uma no estádio de 'grão ervilha' e outra no estádio 'véraison' (início da mudança de cor das bagas).

$\mathrm{O}$ delineamento experimental foi de blocos casualizados, com quatro repetições. A unidade experimental foi composta por duas plantas de videira. Como bordadura, utilizou-se uma fileira entre blocos e uma planta entre parcelas do mesmo bloco. Os tratamentos constaram da aplicação no solo de diferentes fontes de $\mathrm{Ca}^{2+}$ : T1 - testemunha (sem aplicação de $\mathrm{Ca}^{2+}$ no solo); T2 - cloreto de cálcio, $\mathrm{CaCl}_{2}(24 \%$ de $\left.\mathrm{Ca}^{2+}\right)$; T3 - gesso agrícola (16\% de $\mathrm{Ca}^{2+} ; 13 \%$ de enxofre); T4 - Nitrabor $^{\circledR}\left(19 \%\right.$ de $\mathrm{Ca}^{2+} ; 15,5 \%$ de nitrogênio; $0,3 \%$ de boro); T5 - cal hidratada (46\% de $\left.\mathrm{Ca}^{2+}\right)$; T6 - Borra de celulose $\left(29 \%\right.$ de $\left.\mathrm{Ca}^{2+}\right)$. Aplicouse o equivalente a $80 \mathrm{~kg}$ de $\mathrm{Ca}^{2+} \mathrm{ha}^{-1}$, parcelados em três aplicações, realizadas em intervalos de 21 dias: 29 de agosto, 18 de setembro e 09 de outubro de 2007 , coincidindo com o estádio 5 (ponta verde), estádio 27 (início de frutificação - limpeza de cacho) e estádio 31 ('grão ervilha'), respectivamente, conforme escala fenológica proposta por Eichhorn \& Lorenz (1977). A aplicação das fontes de $\mathrm{Ca}^{2+}$ no solo foi efetuada através de um sulco de $10 \mathrm{~cm}$ de profundidade, feito na forma de um quadrado ao redor da planta, a 50 cm do caule da mesma.

Os teores de $\mathrm{K}^{+1}, \mathrm{Ca}^{2+}$ e $\mathrm{Mg}^{2+}$ e suas relações no solo, nas profundidades de $0-15$ e $15-30 \mathrm{~cm}$, foram determinados antes da instalação do experimento (Tabela 1) e em 29 de novembro de 2007 (sete dias antes da colheita). As amostragens de solo foram realizadas ao lado do sulco de aplicação, em dois pontos ao redor de cada planta da parcela. Estas amostragens constituíram uma amostra composta na qual se procedeu à análise química.

Coletaram-se folhas completas (pecíolo + limbo), em 13 de novembro de 2007, no estádio 'véraison'. As amostras foram compostas por quatro folhas por parcela, coletadas do primeiro ramo produtivo, opostas ao primeiro cacho (Comissão..., 2004). Realizou-se análise do teor de $\mathrm{K}^{+1}, \mathrm{Ca}^{2+}, \mathrm{Mg}^{2+}$ e N (total), com base na matéria seca, no laboratório de análises químicas da Universidade Tecnológica Federal do Paraná - UTFPR, Campus Pato Branco, segundo metodologia descrita em Tedesco et al. (1995).

Por ocasião da colheita, em 6 de dezembro 
de 2007, retiraram-se quatro cachos por parcela, dos quais se obteve o peso fresco. Em seguida, os cachos foram divididos em dois grupos: no primeiro, os cachos foram acondicionados em bandejas de isopor e cobertos por filme plástico de $10 \mu \mathrm{m}$ de espessura para avaliação de conservação pós-colheita (atmosfera modificada); no outro, os cachos foram degranados, efetuando-se a contagem e determinação do peso fresco das bagas. Em seguida, uma parte das bagas foi separada para a determinação do teor de

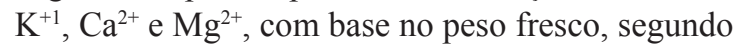
metodologia descrita em Tedesco et al. (1995) e outra parte foi submetida à trituração em multiprocessador eletrônico e, com o suco obtido, procedeu-se à análise de teor de sólidos solúveis totais (SST) e acidez titulável (AT), determinada através de titulação com uma solução de hidróxido de sódio a $0,1 \mathrm{M}$, até $\mathrm{pH}$ 8,1 , de $10 \mathrm{~mL}$ de suco diluído em $100 \mathrm{~mL}$ de água destilada. Além disso, parte do suco foi utilizado para a determinação do teor de antocianinas e flavonoides, seguindo metodologia descrita em Lees \& Francis (1972).

Os cachos para avaliação de conservação em pós-colheita foram mantidos em sala sob temperatura ambiente e, após cinco dias da colheita, avaliaram-se a perda de peso do cacho, o percentual de degrane e de incidência de podridões nas bagas, e os teores de SST e AT.

Os dados foram analisados através do programa computacional 'Genes' (Cruz, 2006), submetendo-os à análise de variância e comparação de médias, pelo teste de Tukey $(P \leq 0,05)$. Os valores expressos em percentual foram transformados por $\operatorname{arc.sen} \sqrt{\frac{\mathrm{x}}{100}}$.

\section{RESULTADOS E DISCUSSÃO}

Observou-se que o teor de $\mathrm{Ca}^{2+}$ no solo foi incrementado significativamente com o uso das fontes de $\mathrm{Ca}^{2+}$, em relação à testemunha, na profundidade de 0-15 cm (Tabela 2). Na profundidade de 15-30 $\mathrm{cm}$, houve maior incremento no teor de $\mathrm{Ca}^{2+}$ no solo, com a utilização de gesso agrícola (T3), que diferiu significativamente dos demais tratamentos. A testemunha (T1) continha o menor teor de $\mathrm{Ca}^{2+}$, não diferindo significativamente de Nitrabor $^{\circledR}$ (T4). Os teores de $\mathrm{K}^{+1}$ e $\mathrm{Mg}^{2+}$ não foram influenciados significativamente pela aplicação das fontes de $\mathrm{Ca}^{2+}$, nas duas profundidades.

$\mathrm{O}$ alto teor de magnésio, observado nas duas profundidades na análise inicial do solo (Tabela 1), manteve-se ao final do experimento (Tabela 2). Este fator manteve as relações $\mathrm{Ca}^{+2} / \mathrm{Mg}^{+2}$ e $\mathrm{Mg}^{+2} / \mathrm{K}^{+1}$ fora dos padrões considerados ideais para a videi- ra. Segundo Giovannini (2001), os valores devem estar entre 3 a 4, para ambas as relações. A relação $\mathrm{Ca}^{+2} / \mathrm{K}^{+1}$ também se manteve superior ao limite recomendado, que é de 9 a 12. Esta última denota a necessidade de suplementar o $\mathrm{K}^{+1}$ do solo através de adubação. Não houve influência significativa dos tratamentos nas três relações nutricionais avaliadas, tanto na profundidade de $0-15 \mathrm{~cm}$ como na de $15-30$ $\mathrm{cm}$ (Tabela 2). O alto teor de magnésio no solo pode ocasionar inibição da absorção de $\mathrm{Ca}^{2+} \mathrm{e} \mathrm{K}^{+1}$, devido à competição entre estes minerais pelo mesmo sítio de absorção das raízes (Moreira et al., 2005).

$\mathrm{O}$ maior teor de $\mathrm{Ca}^{2+}$ na profundidade de 15-30 cm, com a utilização do gesso agrícola, já era esperado. A utilização de gesso agrícola, que é basicamente sulfato de cálcio, favorece a lixiviação de $\mathrm{Ca}^{2+}$ para o subsolo, devido sua solubilidade e reações no solo, aumentando os teores em profundidade e neutralizando a ação tóxica do alumínio (Maria et al., 1993). Porém, Wadt \& Wadt (1999) verificaram que a aplicação de sulfato de cálcio também favoreceu o processo de lixiviação de $\mathrm{K}^{+1}$ e $\mathrm{Mg}^{2+}$, fato que pode acarretar deficiência destes nutrientes nas camadas menos profundas, podendo estes ficarem fora do alcance das raízes. Entretanto, neste experimento, este fato não foi verificado devido ao bom suprimento destes nutrientes na camada superior do solo.

$\mathrm{O}$ teor de $\mathrm{Ca}^{2+}$ no tecido foliar da videira foi incrementado significativamente pelas diferentes fontes de $\mathrm{Ca}^{2+}$, à exceção de borra de celulose (T6), que não diferiu significativamente da testemunha, embora também não tenha diferido das demais fontes de $\mathrm{Ca}^{2+}$ (Tabela 3). Embora a testemunha tenha apresentado o menor percentual de $\mathrm{Ca}^{2+}$ no tecido foliar, este teor $\left(0,162 \mathrm{~g} \mathrm{~kg}^{-1}\right)$ é considerado adequado, dentro dos limites de 0,16 a $0,24 \mathrm{~g} \mathrm{~kg}^{-1}$ (Comissão..., 2004). Este fato pode ser devido ao suprimento de $\mathrm{Ca}^{2+}$ foliar utilizado no vinhedo durante o experimento.

$\mathrm{O}$ teor de $\mathrm{K}^{+1}$ e $\mathrm{Mg}^{2+}$ no tecido foliar não foi influenciado significativamente pela aplicação das fontes de $\mathrm{Ca}^{2+}$ no solo. Quanto ao teor de N, observou-se que o Nitrabor ${ }^{\circledR}$ (T4) proporcionou incremento no tecido foliar, diferindo significativamente das demais fontes, que não diferiram da testemunha. Isto pode ser explicado pela composição do produto comercial Nitrabor ${ }^{\circledR}$, que contém $15,5 \%$ de nitrogênio, enquanto as demais fontes não contêm este nutriente.

No caso do teor de minerais nos frutos, avaliados por ocasião da colheita, observou-se que o $\mathrm{Ca}^{2+}$ total foi superior quando se utilizaram as diferentes fontes deste nutriente no solo, as quais 
diferiram significativamente da testemunha. Os teores de $\mathrm{K}^{+1}$ e magnésio dos frutos não foram influenciados significativamente pelas fontes de $\mathrm{Ca}^{2+}$ aplicadas no solo (Tabela 4).

Quanto às características físico-químicas dos frutos de videira, avaliadas por ocasião da colheita, observou-se que os tratamentos não influenciaram significativamente no peso total de cacho. Porém, o peso médio de bagas foi maior quando se utilizou o Nitrabor ${ }^{\circledR}$ (T4) e o gesso agrícola (T3), que diferiram significativamente da testemunha. As demais fontes não diferiram da testemunha, mas também não diferiram do efeito do gesso agrícola (Tabela 5). Observa-se que houve proporcionalidade entre o aumento do peso de bagas e o aumento do peso total do cacho, embora para esta última característica não houvesse diferença significativa entre os tratamentos. Este fato pode ter sido devido a diferenças no número de bagas/cacho, o qual é definido no ciclo vegetativo anterior. Além disso, neste experimento, efetuou-se raleio com ácido giberélico no início da frutificação (estádio 27). Desse modo, não se pode inferir de forma contundente sobre a influência das fontes de $\mathrm{Ca}^{2+}$ na produtividade do vinhedo.

O papel principal do $\mathrm{Ca}^{2+}$ é o de estruturação e funcionamento das membranas (Sanders et al., 1999). Segundo Tobias et al. (1993), 60\% do $\mathrm{Ca}^{2+}$ celular total está localizado na parede celular. Desse modo, o melhor efeito de Nitrabor ${ }^{\circledR}$ no peso médio de bagas pode ser devido aos demais constituintes deste produto, que contém $15,5 \%$ de nitrogênio e $0,3 \%$ de boro. No caso do gesso agrícola, seu efeito positivo pode ter sido devido ao aporte de enxofre, presente no gesso. Isto porque, só o aporte de $\mathrm{Ca}^{2+}$ não favorece o aumento do peso das bagas, como observado por Lima et al. (2001), os quais aplicaram $\mathrm{CaCl}_{2}$, via imersão do cacho de uvas 'Itália', em pré-colheita. Este tratamento aumentou o teor de $\mathrm{Ca}^{2+}$ total e solúvel no engaço e na baga, porém não proporcionou incremento significativo no peso e volume da baga.

O teor de sólidos solúveis totais (SST) nos frutos não foi influenciado significativamente pelas fontes de $\mathrm{Ca}^{2+}$ aplicadas no solo. Houve pequena alteração na acidez titulável (AT) dos frutos. AAT foi menor quando se utilizou a borra de celulose (T6), que diferiu significativamente da testemunha, porém sem diferir das demais fontes de $\mathrm{Ca}^{2+}$ aplicadas no solo. Por sua vez, Lima et al. (2000) observaram que a aplicação de diferentes concentrações de $\mathrm{CaCl}_{2}$ na uva 'Itália' em pré-colheita, via imersão de cachos, não afetou a AT. Dessa forma, parece que o cálcio não é responsável pela mudança expressiva no conteúdo de SST e AT, nas formas e quantidades aplicadas neste trabalho e no de Lima et al. (2000).

Segundo Vitrac et al. (2000), o $\mathrm{Ca}^{2+}$ é um sinalizador para a biossíntese de antocianinas, a partir de açúcares. Porém, neste trabalho, o teor de antocianinas nos frutos não foi influenciado significativamente pelas fontes de $\mathrm{Ca}^{2+}$ aplicadas no solo. Isto pode ter ocorrido devido ao alto coeficiente de variação observado para os dados (30,3\%), ocasionado pela diferença no grau de maturação de bagas que ocorre em cada cacho. Porém, percebe-se tendência de aumento no teor de antocianinas, principalmente para gesso agrícola, borra de celulose e Nitrabor ${ }^{\circledR}$, em relação à testemunha. Do mesmo modo, Lara et al. (2004) não observaram diferenças significativas no teor de antocianinas em frutos de morango tratados ou não tratados com $\mathrm{CaCl}_{2}$ em pós-colheita.

Nas avaliações de pós-colheita, após cinco dias sob condições de prateleira (temperatura ambiente e atmosfera modificada), a perda de peso foi reduzida significativamente com a utilização de fontes de $\mathrm{Ca}^{2+}$, em relação à testemunha (Tabela 6), o que pode ser devido ao papel do $\mathrm{Ca}^{2+}$ na rigidez da parede celular, reduzindo a perda de água dos frutos. Este fato também foi observado por Hernández-Muñoz et al. (2006) em morangos tratados com glucanato de $\mathrm{Ca}^{2+}$ em pós-colheita e armazenados a $20^{\circ} \mathrm{C}$ por quatro dias, reduzindo a perda de peso dos frutos.

O percentual de degrane também foi reduzido significativamente com o uso das fontes de $\mathrm{Ca}^{2+}$, em relação à testemunha. A predisposição para a separação da baga do pedicelo da ráquis é elemento de avaliação de aptidão de variedades ao transporte, característica muito importante para a uva de mesa. A maioria das uvas apirênicas, como é o caso da 'Vênus', apresentam predisposição genética ao degrane (Colapietra et al., 1995). Porém, técnicas agronômicas, como a adubação, podem influenciar este fator. Cenci \& Chitarra (1994) observaram que a aplicação de $\mathrm{CaCl}_{2}$ na pré-colheita proporcionou aumento do teor de $\mathrm{O}_{2}$ na zona de abscisão, inibindo a atividade das enzimas de degradação da lamela média, a poligalacturonase e a pectinametilesterase, reduzindo, assim, a queda de bagas em cachos de uva 'Niágara Rosada', a qual apresenta elevadas perdas pós-colheita devido ao degrane.

A incidência de podridões foi reduzida significativamente pela aplicação das fontes de $\mathrm{Ca}^{2+}$, em relação à testemunha. Chardonnet et al. (1997) demonstraram que a aplicação de $\mathrm{CaCl}_{2}$ em póscolheita de uva reduziu a degradação da pectina dos frutos causada por Botrytis cinerea. Elmer et al. (2007) também observaram que o $\mathrm{Ca}^{2+}$ aplicado nas folhas de pessegueiro em pré-colheita proporcionou incremento do conteúdo de $\mathrm{Ca}^{2+}$ nos tecidos dos frutos 
e reduziu a incidência e severidade de podridão-parda (Monilinia fructicola) em pós-colheita.

O teor de SST não foi influenciado significativamente pelas fontes de $\mathrm{Ca}^{2+}$ aplicadas no solo. Porém, este teor foi numericamente menor na testemunha, pois o $\mathrm{Ca}^{2+}$ reduz a taxa respiratória, por limitar a difusão dos substratos do vacúolo para o citoplasma (Faust \& Shear, 1972) e, consequentemente, reduz o consumo dos açúcares do fruto durante a respiração, mantendo-os em maiores níveis quando se utilizou $\mathrm{Ca}^{2+}$. A AT dos frutos foi significativamente menor quando se utilizaram fontes de $\mathrm{Ca}^{2+}$ aplicadas no solo, comparativamente à testemunha (Tabela 6). Segundo Silva et al. (1997), o aumento da AT em frutas armazenadas por curtos períodos pode ser explicado pela síntese de ácidos galacturônicos, a partir da hidrólise de constituintes da parede celular, em especial, as pectinas. Neste experimento, a avaliação pós-colheita dos frutos de videira foi realizada aos cinco dias de armazenamento e, provavelmente, os tratamentos com $\mathrm{Ca}^{2+}$ reduziram a degradação da parede celular e a consequente formação de ácidos, observando-se menor teor de AT em relação à testemunha.

Alguns trabalhos demonstram maior conservação pós-colheita de frutos com uso de $\mathrm{Ca}^{2+}$. Lara et al. (2004) observaram que a aplicação pós-colheita de $\mathrm{Ca}^{2+}$ em morangos proporcionou manutenção da integridade da parede celular e lamela média, refletindo maior conservação pós-colheita dos frutos. Esta observação também foi realizada por Natale et al. (2005) em frutos de goiabeira sob aplicação de $\mathrm{Ca}^{2+}$, na forma de calcário no solo, o qual foi efetivo na estruturação e organização das paredes celulares e das lamelas médias, aumentando a vida de prateleira do fruto. Por outro lado, Vizzotto et al. (2002) observaram que a pulverização foliar com $\mathrm{CaO}$ ou $\mathrm{CaCl}_{2}$ em várias épocas, antes da colheita, não teve efeito sobre a qualidade dos pêssegos 'Chiripá' durante o armazenamento refrigerado.

Embora as evidências não sejam totalmente comprovadas, admite-se que próximo à 'véraison' ocorre o rompimento da conexão xilemática no pedúnculo do cacho de uva e, aparentemente, o abastecimento de água e nutrientes minerais do ramo para as bagas torna-se comprometido (Kennedy, 2002). Além disso, segundo Chamel (1989), a alternativa de se aplicar $\mathrm{Ca}^{2+}$ antes da colheita em macieira é discutível, dada à baixa mobilidade do elemento no floema e sua baixa translocação a partir do local de aplicação. Entretanto, como observado neste trabalho (Tabela 4), o aporte de $\mathrm{Ca}^{2+}$ para os frutos foi influenciado pela sua aplicação no solo. Desse modo, estabelecem-se duas hipóteses: que não houve a interrupção completa do fluxo de $\mathrm{Ca}^{2+}$ através do xilema para os frutos após a 'véraison'; ou, que a absorção de $\mathrm{Ca}^{2+}$ pelos tecidos dos frutos tenha ocorrido de forma expressiva antes da fase de interrupção do fluxo xilemático, hipótese mais provável, pois a aplicação de $\mathrm{Ca}^{2+}$ foi realizada antes da 'véraison'. Para testar estas hipóteses, sugere-se que seja realizado um teste com aplicação de $\mathrm{Ca}^{2+}$ no solo antes e após a 'véraison' e verificar seu teor nos frutos, nestas duas situações.

Dentre as fontes de $\mathrm{Ca}^{2+}$ estudadas, destacamse o gesso agrícola, que é um subproduto da indústria de fertilizantes fosfatados; a borra de celulose, que é um resíduo industrial disponível em regiões nas quais empresas de papel e celulose estão instaladas, e a cal hidratada, utilizada na construção civil e amplamente disponível no mercado, o que torna estes produtos de baixo custo de aquisição. Além disso, o Nitrabor ${ }^{\circledR}$, apesar de ter um custo mais elevado, apresenta a vantagem de contribuir com aporte de $\mathrm{N}$ e B, além do $\mathrm{Ca}^{2+}$, aumentando o peso de bagas, o que pode viabilizar sua utilização.

Apesar do suprimento de $\mathrm{Ca}^{2+}$ foliar utilizado no vinhedo, o $\mathrm{Ca}^{2+}$ aplicado no solo influenciou positivamente na qualidade dos frutos. As fontes de $\mathrm{Ca}^{2+}$ proporcionaram redução da AT e tendência de aumento de SST, embora sem significância, tanto na colheita quanto em pós-colheita. Porém, os maiores efeitos foram observados na redução da perda de peso, degrane e incidência de podridões em póscolheita, o que demonstra efeito de manutenção da qualidade da uva 'Vênus', permitindo maior vida de prateleira. Estes fatores justificam a utilização de $\mathrm{Ca}^{2+}$ em aplicação no solo, em videira, desde que antes do estádio 'véraison' e em condições de baixo teor de $\mathrm{Ca}^{2+}$ no solo ou quando este íon estiver em desequilíbrio com o $\mathrm{Mg}^{2+}$, fato observado neste experimento. 
TABELA 1 - Teores de potássio, cálcio e magnésio e suas relações no solo da área experimental antes da aplicação das fontes de cálcio.UTFPR, Campus Pato Branco,2007

\begin{tabular}{|c|c|c|c|c|c|c|}
\hline Profundidade $(\mathrm{cm})$ & $\mathrm{K}^{+1}$ & $\mathrm{Ca}^{+2}$ & $\mathrm{Mg}^{+2}$ & Rel. $\mathrm{Ca}^{+2} / \mathrm{Mg}^{+2}$ & Rel. $\mathrm{Ca}^{+2} / \mathrm{K}^{+2}$ & Rel. $\mathrm{Mg}^{+2} / \mathrm{K}^{+2}$ \\
\hline \multicolumn{7}{|c|}{ - } \\
\hline $0-15$ & 0,52 & 6,5 & 3,8 & 1,7 & 12,5 & 7,3 \\
\hline $15-30$ & 0,34 & 5,0 & 3,7 & 1,4 & 14,7 & 10,9 \\
\hline
\end{tabular}

TABELA 2 - Teores de potássio, cálcio e magnésio e suas relações no solo próximo à colheita dos frutos de videira 'Vênus', nas profundidades de 0-15 e 15-30 cm, em função de diferentes fontes de cálcio aplicadas no solo. UTFPR, Campus Pato Branco, 2007.

\begin{tabular}{|c|c|c|c|c|c|c|}
\hline \multirow[b]{3}{*}{ Tratamento } & $\mathrm{K}^{+1}$ & $\mathrm{Ca}^{+2}$ & $\mathrm{Mg}^{+2}$ & Rel. $\mathrm{Ca}^{+2} / \mathrm{Mg}^{+2}$ & Rel. $\mathrm{Ca}^{+2} / \mathrm{K}^{+2}$ & $\begin{array}{c}\text { Rel. } \mathrm{Mg}^{+2} / \\
\mathrm{K}^{+2}\end{array}$ \\
\hline & \multicolumn{6}{|c|}{ - } \\
\hline & \multicolumn{6}{|c|}{ Profundidade $0-15 \mathrm{~cm}$} \\
\hline T1 & $0,52^{\mathrm{NS}}$ & $6,52 b^{*}$ & $3,82^{\mathrm{NS}}$ & $1,71^{\mathrm{NS}}$ & $12,53^{\mathrm{NS}}$ & $7,35^{\mathrm{NS}}$ \\
\hline $\mathrm{T} 2$ & 0,53 & $7,77 \mathrm{a}$ & 3,99 & 1,95 & 14,79 & 7,60 \\
\hline $\mathrm{T} 3$ & 0,56 & $7,69 \mathrm{a}$ & 3,77 & 2,04 & 13,79 & 6,76 \\
\hline $\mathrm{T} 4$ & 0,55 & $7,58 \mathrm{a}$ & 3,87 & 1,96 & 13,85 & 7,07 \\
\hline T5 & 0,52 & $7,61 \mathrm{a}$ & 3,88 & 1,96 & 14,63 & 7,46 \\
\hline T6 & 0,53 & $7,63 \mathrm{a}$ & 3,61 & 2,12 & 14,45 & 6,83 \\
\hline \multirow[t]{2}{*}{ C.V. $(\%)$} & 21,2 & 3,1 & 8,4 & 8,4 & 26,6 & 30,9 \\
\hline & \multicolumn{6}{|c|}{ Profundidade $15-30 \mathrm{~cm}$} \\
\hline $\mathrm{T} 1$ & $0,33^{\mathrm{NS}}$ & $5,10 \mathrm{c}$ & $3,68^{\mathrm{NS}}$ & $1,39^{\mathrm{NS}}$ & $15,45^{\mathrm{NS}}$ & $11,15^{\mathrm{NS}}$ \\
\hline $\mathrm{T} 2$ & 0,40 & $5,53 \mathrm{~b}$ & 3,75 & 1,48 & 14,01 & 9,48 \\
\hline T3 & 0,35 & $5,89 \mathrm{a}$ & 3,80 & 1,55 & 16,82 & 10,86 \\
\hline $\mathrm{T} 4$ & 0,35 & $5,35 \mathrm{bc}$ & 3,71 & 1,44 & 15,18 & 10,52 \\
\hline $\mathrm{T} 5$ & 0,36 & $5,48 \mathrm{~b}$ & 3,77 & 1,45 & 15,31 & 10,53 \\
\hline T6 & 0,37 & $5,52 \mathrm{~b}$ & 3,70 & 1,49 & 15,12 & 10,14 \\
\hline C.V. $(\%)$ & 19,3 & 2,6 & 5,2 & 5,7 & 16,7 & 18,3 \\
\hline
\end{tabular}

*Médias seguidas de letras distintas diferem entre si, pelo teste de Tukey $(P \leq 0,05)$. NS: não significativo.

$\mathrm{T} 1$ - testemunha (sem aplicação de $\mathrm{Ca}^{2+}$ no solo); T2 - cloreto de cálcio $\left(\mathrm{CaCl}_{2}\right)$; T3 - gesso agrícola; T4 - Nitrabor ${ }^{\circledR} ; \mathrm{T} 5$ - cal hidratada; T6 - borra de celulose.

TABELA 3 - Teores ( $\mathrm{g} \mathrm{kg}^{-1}$, peso seco) de potássio, cálcio, magnésio e nitrogênio em tecido foliar de videira 'Vênus', durante o 'véraison', em função de diferentes fontes de cálcio aplicadas no solo. UTFPR, Câmpus Pato Branco, 2007.

\begin{tabular}{ccccc}
\hline Tratamento & $\mathrm{K}^{+1}$ & $\mathrm{Ca}^{+2}$ & $\mathrm{Mg}^{+2}$ & $\mathrm{~N}$ \\
\hline T1 & $0,171^{\mathrm{NS}}$ & $0,162 \mathrm{~b}^{*}$ & $0,042^{\mathrm{NS}}$ & $0,174 \mathrm{~b}$ \\
$\mathrm{~T} 2$ & 0,192 & $0,197 \mathrm{a}$ & 0,046 & $0,196 \mathrm{~b}$ \\
$\mathrm{~T} 3$ & 0,180 & $0,206 \mathrm{a}$ & 0,043 & $0,179 \mathrm{~b}$ \\
T4 & 0,196 & $0,188 \mathrm{a}$ & 0,041 & $0,280 \mathrm{a}$ \\
T5 & 0,164 & $0,202 \mathrm{a}$ & 0,047 & $0,186 \mathrm{~b}$ \\
T6 & 0,175 & $0,184 \mathrm{ab}$ & 0,041 & $0,185 \mathrm{~b}$ \\
\hline C.V. $(\%)$ & 14,1 & 5,4 & 9,2 & 7,1
\end{tabular}

*Médias seguidas de letras distintas diferem entre si, pelo teste de Tukey $(P \leq 0,05)$. NS: não significativo.

$\mathrm{T} 1$ - testemunha (sem aplicação de $\mathrm{Ca}^{2+}$ no solo); T2 - cloreto de cálcio $\left(\mathrm{CaCl}_{2}\right)$; T3 - gesso agrícola; T4 - Nitrabor ${ }^{\mathbb{\circledR}}$; T5 - cal hidratada; T6 - borra de celulose. 
TABELA 4 - Teores $\left(\mathrm{g} \mathrm{kg}^{-1}\right.$, peso fresco) de potássio, cálcio e magnésio em frutos (película + polpa) de videira 'Vênus', em função de diferentes fontes de cálcio aplicadas no solo. UTFPR, Câmpus Pato Branco, 2007.

\begin{tabular}{cccc}
\hline Tratamento & $\mathrm{K}^{+1}$ & $\mathrm{Ca}^{+2}$ & $\mathrm{Mg}^{+2}$ \\
\hline T1 & $0,055^{\mathrm{NS}}$ & $0,008 \mathrm{~b}^{*}$ & $0,002^{\mathrm{NS}}$ \\
T2 & 0,055 & $0,017 \mathrm{a}$ & 0,002 \\
$\mathrm{~T} 3$ & 0,048 & $0,019 \mathrm{a}$ & 0,001 \\
$\mathrm{~T} 4$ & 0,062 & $0,020 \mathrm{a}$ & 0,002 \\
T5 & 0,041 & $0,019 \mathrm{a}$ & 0,001 \\
T6 & 0,048 & $0,019 \mathrm{a}$ & 0,002 \\
\hline C.V. $(\%)$ & 18,2 & 10,3 & 29,5 \\
\hline
\end{tabular}

*Médias seguidas de letras distintas diferem entre si, pelo teste de Tukey $(P \leq 0,05)$. NS: não significativo.

$\mathrm{T} 1$ - testemunha (sem aplicação de $\mathrm{Ca}^{2+}$ no solo); T2 - cloreto de cálcio $\left(\mathrm{CaCl}_{2}\right)$; T3 - gesso agrícola; T4 - Nitrabor ${ }^{\sqrt{\mathbb{R}}}$; T5 - cal hidratada; T6 - borra de celulose.

TABELA 5 - Características físico-químicas de frutos (película + polpa) de videira ‘Vênus' em função de diferentes fontes de cálcio aplicadas no solo. UTFPR, Câmpus Pato Branco, 2007.

\begin{tabular}{cccccc}
\hline Tratamento & Peso cacho $(\mathrm{g})$ & Peso bagas $(\mathrm{g})$ & $\mathrm{SST}\left({ }^{\circ}\right.$ Brix $)$ & $\begin{array}{c}\mathrm{AT} \\
\left(\mathrm{meq} 100 \mathrm{~mL}^{-1}\right)\end{array}$ & $\begin{array}{c}\text { Antocianinas } \\
\left(\mathrm{mg} 100 \mathrm{~g} \mathrm{~g}^{-1}\right)\end{array}$ \\
\hline T1 & $316,15^{\mathrm{NS}}$ & $4,01 \mathrm{c}$ & $13,0^{\mathrm{NS}}$ & $9,5 \mathrm{a}$ & $22,5^{\mathrm{NS}}$ \\
T2 & 327,35 & $4,14 \mathrm{bc}$ & 13,2 & $8,9 \mathrm{ab}$ & 26,2 \\
T3 & 359,03 & $4,55 \mathrm{ab}$ & 14,0 & $8,6 \mathrm{ab}$ & 35,7 \\
T4 & 379,45 & $4,88 \mathrm{a}$ & 13,0 & $8,9 \mathrm{ab}$ & 29,0 \\
T5 & 343,75 & $4,38 \mathrm{bc}$ & 13,7 & $8,6 \mathrm{ab}$ & 24,0 \\
T6 & 336,99 & $4,20 \mathrm{bc}$ & 14,3 & $8,1 \mathrm{~b}$ & 29,7 \\
\hline C.V. $(\%)$ & 11,3 & 4,8 & 6,1 & 5,3 & 30,3 \\
\hline
\end{tabular}

*Médias seguidas de letras distintas diferem entre si, pelo teste de Tukey $(P \leq 0,05)$. NS: não significativo.

$\mathrm{T} 1$ - testemunha (sem aplicação de $\mathrm{Ca}^{2+}$ no solo); T2 - cloreto de cálcio $\left(\mathrm{CaCl}_{2}\right)$; T3 - gesso agrícola; T4 - Nitrabor ${ }^{\circledR} ; \mathrm{T} 5$ - cal hidratada; T6 - borra de celulose.

TABELA 6 - Conservação pós-colheita de frutos* de videira 'Vênus' em função de diferentes fontes de cálcio aplicadas no solo. UTFPR, Campus Pato Branco, 2007.

\begin{tabular}{cccccc}
\hline Tratamento & Perda de peso (\%) & Degrane (\%) & Podridões (\%) & SST $\left({ }^{\circ}\right.$ Brix) & AT $\left(\right.$ meq $\left.100 \mathrm{~mL}^{-1}\right)$ \\
\hline T1 & $15,63 \mathrm{a} * *$ & $5,18 \mathrm{a}$ & $3,8 \mathrm{a}$ & $13,35^{\mathrm{NS}}$ & $10,2 \mathrm{a}$ \\
T2 & $10,83 \mathrm{~b}$ & $2,63 \mathrm{~b}$ & $0,7 \mathrm{~b}$ & 14,75 & $9,30 \mathrm{~b}$ \\
T3 & $10,20 \mathrm{~b}$ & $3,28 \mathrm{~b}$ & $0,4 \mathrm{~b}$ & 13,95 & $9,27 \mathrm{~b}$ \\
T4 & $10,98 \mathrm{~b}$ & $2,78 \mathrm{~b}$ & $0,3 \mathrm{~b}$ & 14,15 & $9,37 \mathrm{~b}$ \\
T5 & $11,20 \mathrm{~b}$ & $2,60 \mathrm{~b}$ & $0,4 \mathrm{~b}$ & 14,30 & $9,35 \mathrm{~b}$ \\
T6 & $11,15 \mathrm{~b}$ & $2,73 \mathrm{~b}$ & $0,7 \mathrm{~b}$ & 14,70 & $9,02 \mathrm{~b}$ \\
\hline C.V. $(\%)$ & 3,4 & 5,6 & 18,9 & 5,5 & 3,0 \\
\hline
\end{tabular}

*Avaliações de frutos após cinco dias da colheita, armazenados sob atmosfera modificada e temperatura ambiente. **Médias seguidas de letras distintas diferem entre si, pelo teste de Tukey $(P \leq 0,05)$. NS: não significativo.

$\mathrm{T} 1$ - testemunha (sem aplicação de $\mathrm{Ca}^{2+}$ no solo); T2 - cloreto de cálcio $\left(\mathrm{CaCl}_{2}\right)$; T3 - gesso agrícola; T4 - Nitrabor ${ }^{\circledR} ; \mathrm{T} 5$ - cal hidratada; T6 - borra de celulose.

\section{CONCLUSÕES}

1- Em geral, as fontes de $\mathrm{Ca}^{2+}$ proporcionaram maior teor de $\mathrm{Ca}^{2+}$ no solo, folhas e frutos.

2- Nitrabor $^{\circledR}$ e gesso agrícola aumentaram o peso médio das bagas.

3- As fontes de $\mathrm{Ca}^{2+}$ reduziram a perda de peso, o degrane e a incidência de podridões dos frutos em pós-colheita.

\section{REFERÊNCIAS}

ANUÁRIO BRASILEIRO DAFRUTICULTURA. Cenário e perfil. Santa Cruz do Sul: Gazeta Santa Cruz, 2008. 128p.

CENCI, S.A.; CHITARRA, M.I.F. Controle de abscisão pós-colheita de uva 'Niágara Rosada' (Vitis labrusca L. x $V$. vinifera L.): mecanismos decorrentes 
da aplicação de ANA e cálcio no campo. Revista Brasileira de Fruticultura, Jaboticabal, v.16, n.1, p.146-155, 1994.

CHAMEL, A.R. Permeability characteristics of isolated Golden Delicious apple fruit cuticles with regard to calcium. Journal of the American Society for Horticultural Science, Mount-Vernon, v.114, n.5, p.804-809, 1989.

CHARDONNET, C.; L'HYVERNAY, A.; DONECHE, B. Effect of calcium treatment prior to Botrytis cinerea infection on the changes in pectic composition of grape berry. Physiological and Molecular Plant Pathology, London, v.50, n.4, p.213-218, 1997.

COLAPIETRA, M.; TARRICONE, L.; TAGLIENTE, G. Determinazione delle caratteristiche morfoproduttive dei vitigni di uva da tavola. Verona L'Informatore Agrário, v.51, n.49, p.5-34, 1995. Suplemento

COMISSÃO DE QUÍMICA E FERTILIDADE DO SOLO - RS/SC. Manual de adubação e calagem para os Estados do Rio Grande do Sul e de Santa Catarina. 10. ed. Porto Alegre: Sociedade Brasileira de Ciência do Solo - Núcleo Regional Sul/UFRGS, 2004. 400p.

CRUZ, C.D. Programa genes: estatística experimental e matrizes. Viçosa: UFV, 2006. 285p.

DECHEN, A.R. Acúmulo de nutrientes pela videira (Vitis labrusca $\mathrm{x}$ Vitis vinifera L.) cv. 'Niagara Rosada', durante um ciclo vegetativo. 1979. $133 \mathrm{f}$. Dissertação (Mestrado em Agronomia) - Escola Superior de Agricultura “Luiz de Queiroz", Universidade de São Paulo, Piracicaba, 1979.

EICHHORN, K.W. \& LORENZ, D.H. Phänologische entwincklungsstadien der rebe. Nachrichtenblatt des Deutschen Pflanzenschutzdienstes, Stuttgart, v.29, n.2, p.119-129, 1977.

ELMER, P.A.G.; SPIERS, T.M.; WOOD, P.N. Effects of pre-harvest foliar calcium sprays on fruit calcium levels and brown rot of peaches. Crop Protection, Oxford, v.26, n.1, p.11-18, 2007.

FAUST, M.; SHEAR, C.B. The effect of calcium on the respiration of apples. Journal of the American Society for Horticultural Science, Mount-Vernon, v.97, n.3, p.434-439, 1972.
GIOVANNINI, E. Uva agroecológica. 2. ed. Porto Alegre: Renascença, 2001. 136p.

HERNÁNDEZ-MUÑOZ, P.; ALMENAR, E.; OCIO, M.J.; GAVARA, R. Effect of calcium dips and chitosan coatings on postharvest life of strawberries (Fragaria $\mathrm{x}$ ananassa). Postharvest Biology and Technology, Amsterdam, v.39, n.3, p.247-253, 2006.

HIROCE, R.; OJIMA, M.; GALLO, J.R.; BATAGLIA, O.C.; FURLANI, P.R.; FURLANI, A.M.C. Composição mineral e exportação de nutrientes pelas colheitas de frutos tropicais e temperados. In: $\mathrm{CON}$ GRESSO BRASILEIRO DE FRUTICULTURA, 5 ., 1979, Pelotas. Anais... Pelotas: Sociedade Brasileira de Fruticultura, 1979. p.179-189.

HO, L.C.; HAND, D.J.; FUSSELL, M. Improvement of tomato fruit quality by calcium nutrition. Acta Horticulturae, Wageningen, n.481, p.463-468, 1987.

KENNEDY, J. Understanding grape berry development. San Rafael: Practical Winery and Vineyard, 2002. 5 p.

LARA, I.; GARCÍA, P.; VENDRELL, M. Modifications in cell wall composition after cold storage of calcium-treated strawberry (Fragaria $\times$ ananassa Duch.) fruit. Postharvest Biology and Technology, Amsterdam, v.34, n.3, p.331-339, 2004.

LEES, D.H.; FRANCIS, F.J. Standardization of pigment analyses in cranberries. HortScience, Alexandria, v.7, n.1, p.83-84, 1972.

LIMA, M.A.C.; ALVES, R.E.; ASSIS, J.S.; FILGUEIRAS, H.A.C.; COSTA, J.T.A. Qualidade, fenóis e enzimas oxidativas de uva 'Itália' sob influência do cálcio, durante a maturação. Pesquisa Agropecuária Brasileira, Brasília, v.35, n.12, p.2493-2499, 2000.

LIMA, M.A.C.; ASSIS, J.S.; ALVES, R.E.; COSTA, J.T.A.; MELO, F.I.O. Influência do cálcio nas características físicas e no teor de cálcio durante desenvolvimento e maturação da uva 'Itália'. Pesquisa Agropecuária Brasileira, Brasília, v.36, n.1, p.97-103, 2001.

MANGANARIS, G.A.; VASILAKAKIS, M.; DIAMANTIDIS, G.; MIGNANI, I. The effect of postharvest calcium application on tissue calcium concentration, quality attributes, incidence of flesh 
browning and cell wall physicochemical aspects of peach fruits. Food Chemistry, New York, v.100, n.4, p.1385-1392, 2007.

MARIA, I.C.; ROSSETTO, R.; AMBROSANO, E.J.; CASTRO, O.M. Efeito da adição de diferentes fontes de cálcio no movimento de cátions em colunas de solo. Scientia Agricola, Piracicaba, v.50, n.1, p.87-98, 1993.

MOREIRA, A.; CARVALHO, J.G.; EVANGELISTA, A.R. Relação cálcio e magnésio na fertilidade de um latossolo vermelho escuro distrófico cultivado com alfafa. Ciência e Agrotecnologia, Lavras, v.29, n.4, p.786-794, 2005.

NATALE, W.; MARCHAL, J. Absorção e redistribuição de nitrogênio $\left({ }^{15} \mathrm{~N}\right)$ em Citrus mitis Bl. Revista Brasileira de Fruticultura, Jaboticabal, v.24, n.1, p.183-188, 2002.

NATALE, W.; PRADO, R.M.; MÔRO, F.V. Alterações anatômicas da parede celular de frutos de goiabeira induzidas pelo cálcio. Pesquisa Agropecuária Brasileira, Brasília, v.40, n.12, p.1239-1242, 2005.

SANDERS, D.; BROWNLEE, C.; HARPER, J.F. Communicating with calcium. Plant Cell, Rockville, v.11, n.4, p.691-706, 1999.

SIDDIQUI, S.; BANGERTH, F. Effect of pre-harvest application of calcium on flesh firmness and cellwall composition of apples - influence of fruit size. Journal of Horticultural Science, Ashford, v.70, n.2, p.263-269, 1995.
SILVA, R.; FRANCO, C.M.L.; GOMES, E. Pectinases, hemicelulases e celulases, ação, produção e aplicação no processamento de alimentos: revisão. Boletim da Sociedade Brasileira de Ciência e Tecnologia de Alimentos, Campinas, v.31, n.2, p.249-260, 1997.

TEDESCO, M.J.; GIANELLO, C.; BISSANI, C.A.; BOHNEN, H.; VOLKWEISS, S.J. Análise de solo, plantas e outros materiais. 2. ed. Porto Alegre: Departamento de Solos, UFRGS, 1995. 174p.

TOBIAS, R.B.; CONWAY, W.S.; SAMS, C.E. Cell wall composition of calcium-treated apples inoculated with Botrytis cinerea. Phytochemistry, London, v.32, n.1, p.35-39, 1993.

VITRAC, X.; LARRONDE, F.; KRISA, S.; DECENDIT, A.; DEFFIEUX, G.; MÉRILLON, J.M. Sugar sensing and $\mathrm{Ca}^{2+}$-calmodulin requirement in Vitis vinifera cells producing anthocyanins. Phytochemistry, London, v.53, n.6, p.659-665, 2000.

VIZZOTTO, M.; ANTUNES, P.L.; BRACKMANN, A; DALBOSCO, V. Aplicação de cálcio em précolheita na conservação de pêssego [Prunus persica (L.) Batsch.], cv. Chiripá. Revista Brasileira de Agrociência, Pelotas, v.8 n.1, p.31-35, 2002.

WADT, P.G.S.; WADT, L.H.O. Movimentação de cátions em amostras de um latossolo vermelho-amarelo incubadas com duas fontes de cálcio. Scientia Agricola, Piracicaba, v.56, n.4, p.1157-1164, 1999. 